\title{
Assessment of Optimized Process Parameters for Superior Bioactive Metabolite Production by Nonomuraea longicatena VSM-16 using Response Surface Methodology
}

\author{
Ushakiranmayi Managamuri ${ }^{1}$, Muvva Vijayalakshmi ${ }^{1}$, Venkata Siva Rama Krishna Ganduri ${ }^{2}$, Satish Babu Rajulapati ${ }^{3}$, Sudhakar Poda ${ }^{4 *}$ \\ 'Department of Botany and Microbiology, Acharya Nagarjuna University, Nagarjuna nagar, Guntur, Andhra Pradesh, INDIA. \\ 2Department of Biotechnology, Koneru Lakshmaiah Education Foundation, Vaddeswaram, Guntur, Andhra Pradesh, INDIA. \\ ${ }^{3}$ Department of Biotechnology, National Institute of Technology, Warangal, Telangana, INDIA. \\ ${ }^{4}$ Department of Biotechnology, Acharya Nagarjuna University, Nagarjuna Nagar, Guntur, Andhra Pradesh, INDIA.
}

\begin{abstract}
Objectives: The present work was carried out to check the capability of novel actinobacterium, Nonomuraea longicatena (VSM-16) for bioactive metabolite production and optimization of its process parameters by statistical and mathematical modeling. Methods: Response Surface Methodology (RSM) regression evaluation was done to fit the experimental data of each response with the aid of second order polynomial. Unstructured kinetic models had been developed for growth, substrate utilization and bioactive metabolite production (in terms of responses). Model based kinetic parameters were estimated and the profiles of bioactive metabolite production, substrate utilization and growth had been drawn. Results: The results have shown accurate interaction among process variables at optimized values of incubation time at 8-9 days, $\mathrm{pH}$ at 8-9, temperature at $30-31{ }^{\circ} \mathrm{C}$, concentrations of Mannitol at $2-2.2 \%$ and Biopeptone at $1.5-1.7 \%$ and the data have been effectively fitted into second-order polynomial models. Under these conditions, the responses (zones of inhibition) of various organisms Staphylococcus aureus, Streptococcus mutans,
\end{abstract}

Xanthomonas campestris, Pseudomonas aeruginosa and Candida albicans have been also matched with experimental and predicted consequences. Conclusion: The zones of inhibition (responses) for the organisms had been also determined to be best fitted with experiment and model values. Key words: Bioactive metabolites, Mathematical modeling, Nonomuraea longicatena, Optimization, Regression Analysis, Response Surface Methodology.

Correspondence

Dr. Sudhakar Poda,

Department of Biotechnology, Acharya Nagarjuna University, Nagarjuna Nagar, Guntur, Andhra Pradesh, INDIA.

Phone: +91 9000122929

Email: sudhakarpodha@gmail.com

DOI: 10.5530/jyp.2019.11.77

\section{INTRODUCTION}

To combat and reverse the spread of antibiotic resistance pathogens and to cure dreadful diseases like cancer, new drugs are at a great demand. Nature remains as the ingenious source of new compounds. ${ }^{1}$ The most promising source for the biologically active natural compounds are the marine micro-organisms which are currently of great interest due to their efficiency to produce array of various metabolites. Biologically active natural compounds produced by actinobacterium are structurally exciting, many of them have been exploited by the pharmaceutical industry as potent drugs and lead molecules that cannot be found in the terrestrial micro-organisms ${ }^{2}$ and some of which can be used in the process of drug development. $^{3}$

Marine actinobacterium are found to be a rich source of numerous secondary metabolites with robust biological activities. ${ }^{4}$ Actinobacterium are considered to be wealthy abundant source for the production of diverse novel bioactive compounds, of which most of them are reported to be antibacterial, antifungal, anticancer and immunosuppressive compounds. ${ }^{5}$ The unconventional compounds simplify the improvement of new and novel drugs with greater therapeutic efficiency and few side effects. ${ }^{6}$ Hence there is an urgent need for exploring the secondary metabolites produced by these micro-organisms. Production of the bioactive metabolites is notably stimulated by nutritional and cultural conditions. Several environmental factors which includes temperature, $\mathrm{pH}$ and incubation period play a major role in the production of antimicrobial agents. ${ }^{7}$ In addition to the physico-chemical factors the components like carbon, nitrogen, concentration of sodium chloride also play a prime position in production of bioactive metabolites. ${ }^{8}$ The optimization of the process parameters is very critical in order to achieve highest level of metabolite production. ${ }^{9}$

RSM is a critical analytical tool (a set of statistical and mathematical techniques) in designing the optimization process characteristic of multiple independent and dependent variables. ${ }^{10,11}$ The relative significance of several variables and the interactive effects among the variables can be evaluated concurrently. ${ }^{12}$ Conventional method based optimization involves the analysis of one-factor-at-a-time which is time consuming and laborious and the factors interactive effects of the variables are ignored and misleading conclusions may be drawn. It is therefore indispensable to design the procedure to maximize the highest yielding quantities of bioactive metabolites with conserved functional properties. Hence RSM is considered more favorable compared to the classical approach-based optimization and is an ideal strategy for standardizing the process variables. ${ }^{13}$

For this type of fermentation, the standard differential mass balance equations for three components had been well established by applying Monod equation linking substrate concentration to the specific growth rate. Further the evaluation of assumed unstructured mathematical models with experimental facts for comparison in order to find the best model that could describe the whole microbial system, which are more 
effective in elucidating the fermentation profiles of microbial process for bioproducts $^{14-17}$

Thus, the present study is targeted to evaluate the optimized conditions such as temperature, $\mathrm{pH}$, concentrations of mannitol and biopeptone for the bioactive metabolite production by VSM 16 and to further optimize the conditions for maximizing the yield of the bioactive metabolite using RSM. The purpose of research is also to assess the kinetic parameters of bioactive metabolite production from Nonomuraea longicatena strain VSM 16 (KU507597).

\section{MATERIALS AND METHODS}

\section{Isolation}

The marine sediment samples were collected at different depths from the Bay of Bengal of coastal Andhra Pradesh, India and air dried. The air-dried sediment sample was pre-treated with calcium carbonate $(10: 1 \mathrm{w} / \mathrm{w})$ and incubated at $37^{\circ} \mathrm{C}$ for 4 days. The pre-treated sediment sample was suspended in sterile distilled water $(1 \mathrm{~g}$ in $100 \mathrm{ml})$. Serial dilutions were prepared and $100 \mu \mathrm{l}$ of $10^{-4}$ dilution was spread onto the surface of Hemic acid vitamin agar containing $0.1 \%$ Hemic acid, $0.05 \%$ disodium hydrogen phosphate, $0.17 \%$ potassium chloride, $0.005 \%$ $\mathrm{MgSO}_{4} .7 \mathrm{H}_{2} \mathrm{O}, 0.001 \% \mathrm{FeSO}_{4} .7 \mathrm{H}_{2} \mathrm{O}, 0.002 \% \mathrm{CaCO}_{3}, 0.05 \% \mathrm{~B}$ Vitamins, $0.005 \%$ cycloheximide and $2 \%$ agar $(\mathrm{pH} 8)$ supplemented with nalidixic acid $\left(50 \mu \mathrm{gml}^{-1}\right)$ and secnidazole $\left(50 \mu \mathrm{gml}^{-1}\right)$. After incubation for two weeks at $30^{\circ} \mathrm{C}$, distinct strain was selected and maintained by sub culturing on yeast extract malt extract dextrose (YMD) agar medium at $4^{\circ} \mathrm{C}$ for further study.

\section{Identification}

The promising actinomycetes strain VSM-16 was identified as Nonomuraea longicatena VSM 16 with the aid of cultural, morphological, physiological and biochemical studies along with $16 \mathrm{~S}$ rDNA analysis. The rDNA sequence was deposited in the NCBI GenBank with an accession number KU507597. The strain was maintained on YMD agar medium at $4^{\circ} \mathrm{C}$. The purpose of the present work was to optimize the culture conditions for enhancing the production of bioactive metabolites by the strain using RSM.

\section{Statistical optimization design}

RSM is used for modeling and analysis of the problems in which the production of the response is influenced by several variables. RSM is implemented to optimize the bioactive metabolite production by VSM-16 with a purpose for finding the favorable conditions. Central Composite Design (CCD) of the RSM was employed to optimize the process parameters, as per Table 1 for the bioactive metabolite production by VSM-16 and its antimicrobial activity against 5 responses Staphylococcus aureus, Streptococcus mutans, Xanthomonas campestris, Pseudomonas aeruginosa and Candida albicans (in terms of Zone of inhibition) (Table S1). Range and central point value of all the 5 variables are shown in the Table 1.

The following equation represents the coded process variables

$$
x=\left(X_{i}-X_{0}\right) / \Delta x
$$

Where $x$ is dimensionless coded value, $X_{i}$ is actual value of variables, $X_{0}$ is the actual value of the variables at the centre point and $\Delta \mathrm{X}$ is Step change value. The information obtained from experiments was fitted with the second order polynomial equation that is as follows

$Y=\beta_{0}+\sum_{i=1}^{n} \beta_{i} X_{i}+\left(\sum_{i=1}^{n} \beta_{i i} X_{i}\right)^{2}+\sum_{i=1}^{n-1} \sum_{j=i+1}^{n} \beta_{i j} X_{i} X_{j}$

Where $Y$ is predicted response, $\beta_{0}$ is intercept coefficient, $\beta_{i}$ is the linear coefficient, $\beta i j$ is the interaction coefficients, $\beta_{i i}$ is the quadratic coefficients, $X_{i}$ and $X_{j}$ are coded values of the five additive variables under
Table 1: Experimental range of factors studied using CCD in terms of coded and actual factors.

\begin{tabular}{ccccc} 
& & \multicolumn{3}{c}{$\begin{array}{c}\text { Actual levels of coded } \\
\text { factors }\end{array}$} \\
\cline { 3 - 5 } Factors & Symbols & -1 & 0 & +1 \\
& & (Low) & (Middle) & (High) \\
\hline Time of incubation (days) & $A$ & 9 & 10 & 11 \\
$\mathrm{pH}$ & $B$ & 7 & 8 & 9 \\
$\begin{array}{c}\text { Temperature }\left({ }^{\circ} \mathrm{C}\right) \\
\text { Concentration of Mannitol } \\
(\% \mathrm{w} / \mathrm{v})\end{array}$ & $\mathrm{C}$ & 30 & 35 & 40 \\
$\begin{array}{c}\text { Concentration of Biopeptone } \\
(\% \mathrm{w} / \mathrm{v})\end{array}$ & $D$ & 1 & 1.5 & 2 \\
\hline & $E$ & 0.5 & 1 & 1.5 \\
\hline
\end{tabular}

study. 3D plots were generated by varying two variables with the experimental range with the other variable constant at the central point. Fractional factorial design with center points that are augmented with a group of "star points" allows estimation of curvature. ${ }^{18}$

\section{Statistical analysis}

Second order polynomial model was applied to predict the response variables and the data analysis was carried out by means of Analysis of Variance (ANOVA) and the adequacy of the model was predicted through regression analysis $(R 2)$. The values were considered to be significant while the $p$-value $<0.05$. The quality of the fit of the polynomial model was expressed by value of correlation coefficient $(R 2)$. The main indicators for determining the significance and the adequacy of the model applied include F-value (Fisher variation ratio), probability value (Prob $>$ F) and Adequate Precision. Additionally, the numerical optimization was carried out to determine the optimum values of the independent variable.

\section{Kinetic Model development}

Primary mathematical and unstructured kinetic models quantitatively elucidate the substrate utilization and growth-related production formation kinetics through Monod model and logistic equations, in a batch system. ${ }^{19-21}$ Models of Logistic (L) and Modified Luedeking-Piret (MLP) and Logistic Incorporated Modified Leudeking-Piret (LIMLP) were used to duplicate the cell proliferation, Substrate utilization and antimicrobial metabolite productions of the strain, as per Mangamuri et al. 2016, 2017. ${ }^{22,23}$ The data obtained from the models were used to calculate all the kinetic parameters involved in fermentation.

\section{RESULTS}

\section{Statistical optimization design}

The relationship between the process variables and the response functions in terms of antimicrobial activity of bioactive metabolites measured as zone of inhibition against test pathogens $S$. aureus, S. mutans, X. campestris, $P$. aeruginosa and C. albicans. The process variables were identified by five factor inscribed central composite design. The experimental values of the bioactive metabolite production by the strain and its antimicrobial effects against the 5 test pathogens (responses) is measured as zones of inhibition $(\mathrm{mm})$. The experimental values were subjected to multiple regression analysis using RSM to fit the second-order polynomial equations (Equation 2). Experimental values of the 5 responses obtained were nearer to the anticipated values that indicate the model is satisfactory according to the experimental design (Supplementary Table 1). The effect of the variables on the five responses was executed through a randomized experimental run. The impact of the bioactive metabolite produced by the strain was measured as zone of inhibition against the 
five responses ranged from $14 \mathrm{~mm}$ to $17 \mathrm{~mm}$ for $S$. aureus, $14 \mathrm{~mm}$ to $18 \mathrm{~mm}$ for $S$. mutans, $14 \mathrm{~mm}$ to $18 \mathrm{~mm}$ for X. campestris, $13 \mathrm{~mm}$ to $16 \mathrm{~mm}$ for $P$. aeruginosa and $13 \mathrm{~mm}$ to $16 \mathrm{~mm}$ for C. albicans.

To analyse the significance of all the factors under study, ANOVA was performed and the results are presented in the Table 2. The table summarizes the regression coefficient $\left(R^{2}\right)$; Sum of Squares (SS), Standard Errors (SE), F-value and $P$-Value. $P$-value is the probability value which determines the effect in the model that was significant statistically. ${ }^{24}$ The smaller the value of $p$ the corresponding coefficient is considered to be more significant. ${ }^{25}$ To have higher confidence levels of $95 \%$ to $99 \%$ the value of $\mathrm{p}$ should be equal to 0.05 and 0.01 for the effect to be statistically significant. ${ }^{26}$ The Fisher's statistical test was employed to determine the significance of each factor where the significance degree was ranked based on the F-ratio value. ${ }^{27}$

\section{Optimum operating conditions and corresponding results}

Following the same procedure reported $b y^{25}$ the optimum values of incubation time, $\mathrm{pH}$, temperature, concentration of mannitol and biopeptone were obtained. As referred to desirability function a multiresponse method for optimizing the operational conditions are employed. Finally, the optimum values of incubation time, $\mathrm{pH}$, temperature have been found to be 8 days, $30^{\circ} \mathrm{C}, \mathrm{pH} 8.0$ and concentration of mannitol at $2 \%$ and biopeptone at $1.5 \%$, respectively.

\section{Checking the model adequacy}

Statistics used to check the adequacy of the models at a confidence level of $99 \%$ are summarized in Table 2. The coefficient of determination $\left(R^{2}\right)$ indicate the proportion of the total variability of the model explained and suggested that for a good fit model. $R 2$ should be close to the value 1 and should be at least $0.8 .^{28}$ Hence the $R$ value reflected to be a very good fit between the observed and the predicted response values. Potential problem of the fit model is that it always increases with added factors even if the factors are not significant. ${ }^{29}$ Hence adjusted $R 2$ is used to assess the model adequacy since it is adjusted for the number of terms in the model. ${ }^{26}$ Adjusted $R 2$ is adjusted for the size of the model in way it decreases the insignificant factors added to the model. ${ }^{29}$ The $R 2$ value higher than 0.9 indicates that, the regression model fit the data very well. ${ }^{30}$ The Coefficient of Variation $(\mathrm{CV})$ is the standard deviation expressed as a percentage of the mean and should be less than $10 \%{ }^{26}$ The ANOVA variance statistics are given in the Table 2. The suggested sequential model sum of squares and lack of fit tests (showing degrees of freedom; Mean square, F-value, $p$-value), model summary statistics for the best outcome quadratic model, for all the five responses, is given in (Supplementary Table 2). The model was found to be statistically significant since the Prob $>F$ value of the model for all the five responses was found to be $<0.00001$ and $F$ values of the model for five responses are given in Table S2 and imply that the model is significant.

\section{Response surface analysis of bioactive metabolite production}

Optimization of the selected five variables viz. incubation time, $\mathrm{pH}$, temperature, concentration of mannitol and biopeptone, a 10-factorial design with central point was constructed. Highest activity (zone of inhibition represented in $\mathrm{mm}$ ) of the bioactive metabolite produced by the strain against the five responses was obtained when the incubation time of 8 days, $\mathrm{pH}$ of 7 , temperature of $30^{\circ} \mathrm{C}$, concentrations of mannitol at $2 \%$ and bio peptone at $1.5 \%$. The maximum zone of inhibitions against all the five responses was found to be $17 \mathrm{~mm}$ (for S. aureus), $18 \mathrm{~mm}$ (for S. mutans), $18 \mathrm{~mm}$ (for X. campestris), $16 \mathrm{~mm}$ (for P. aeruginosa) and $16 \mathrm{~mm}$ (for C. albicans).

\section{DISCUSSION}

The interactive effects of the process variables on the five responses are illustrated in 3D (three-dimensional surface plots). Analysis of the 3D plots represents that all the three parameters showed the tremendous impact at the beginning and reached maximum and further increase of the range of values and concentration showed a negative effect on the production of bioactive metabolite by VSM-16 and its effect against the responses. Figure 1-3 showed the zones of inhibition $(\mathrm{mm})$ against the five responses. The increase in the production of bioactive metabolite by VSM-16 metabolite could be achieved with incubation time of 8 days, $\mathrm{pH}$ at 8 , temperature range between $30^{\circ} \mathrm{C}$, concentration of mannitol between 2 and concentration of biopeptone IS 1.5\% Beyond these ranges, the zone of inhibition produced by the bioactive metabolite decreased.

RSM is a method that is effective statistically and determines the coefficients of the mathematical model and optimum conditions using minimum set of experiments..$^{21,31}$ The values of the responses obtained from the confirmation experiments and predicted values obtained through optimization approach are presented in the Supplementary Table 1 . The fit summary produced by using the Design-Expert Version 8 recommends the quadratic and linear models to produce the bioactive metabolite by $N$. longicatena VSM 16. ANOVA variance was executed to study the relationships and the results of the second order response surface fitting were given in the Table 2 and Supplementary Table 2. The $P$ - value of the models for the bioactive metabolite production is presented in Supplementary Table 2. The model was considered statistically significant if the p-value was less than $0.05 .^{32}$ The lower value of $P$ narrates the mutual interactions between the variables and indicates the importance of these variables in the model. ${ }^{33}$ ANOVA analysis revealed

\begin{tabular}{|c|c|c|c|c|c|}
\hline \multirow[b]{2}{*}{ Statistics } & \multicolumn{5}{|c|}{ Response } \\
\hline & $\begin{array}{c}\text { S. } \\
\text { aureus }\end{array}$ & $\begin{array}{c}\text { S. } \\
\text { mutans }\end{array}$ & $\begin{array}{c}X . \\
\text { Campestris }\end{array}$ & $\begin{array}{c}P . \\
\text { aeruginosa }\end{array}$ & $\begin{array}{c}\text { C. } \\
\text { albicans }\end{array}$ \\
\hline $\mathbf{R}^{2}$ & 0.9112 & 0.9581 & 0.9504 & 0.9455 & 0.9247 \\
\hline Adjusted $\mathbf{R}^{2}$ & 0.9499 & 0.9292 & 0.9162 & 0.9370 & 0.9652 \\
\hline Predicted $\mathrm{R}^{2}$ & 0.9447 & 0.8566 & 0.8453 & 0.9642 & 0.9652 \\
\hline Adequate & 13.988 & 20.004 & 16.452 & 9.158 & 14.288 \\
\hline \multicolumn{6}{|l|}{ Precession } \\
\hline $\mathrm{CV} \%$ & 2.55 & 2.73 & 2.89 & 2.31 & 3.03 \\
\hline
\end{tabular}
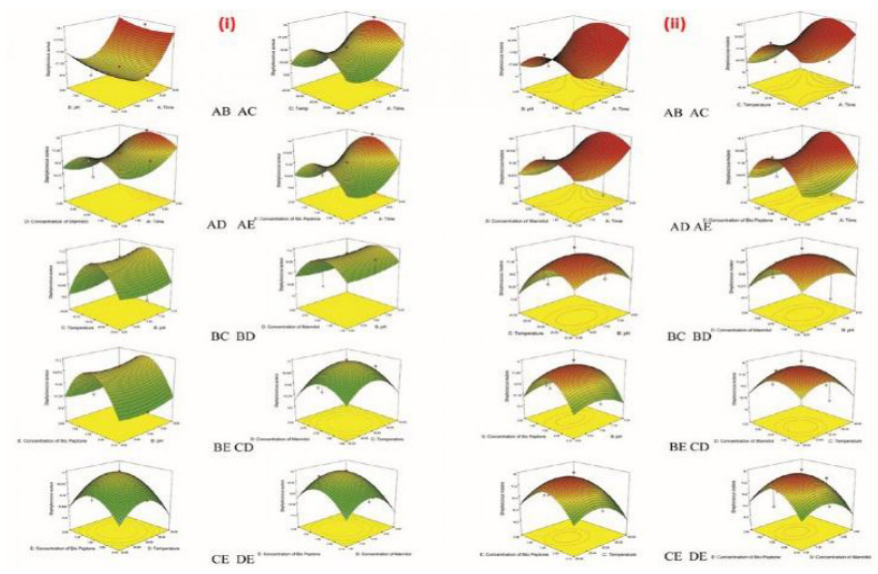

Figure 1: Response surface 3D plots showing the interactive effects of selective variables on Zone of inhibition ( $\mathrm{mm}$ ) of the bioactive compound production by Nonomuraea longicatena VSM-16 against (i) S. aureus, (ii) S.mutans response. 

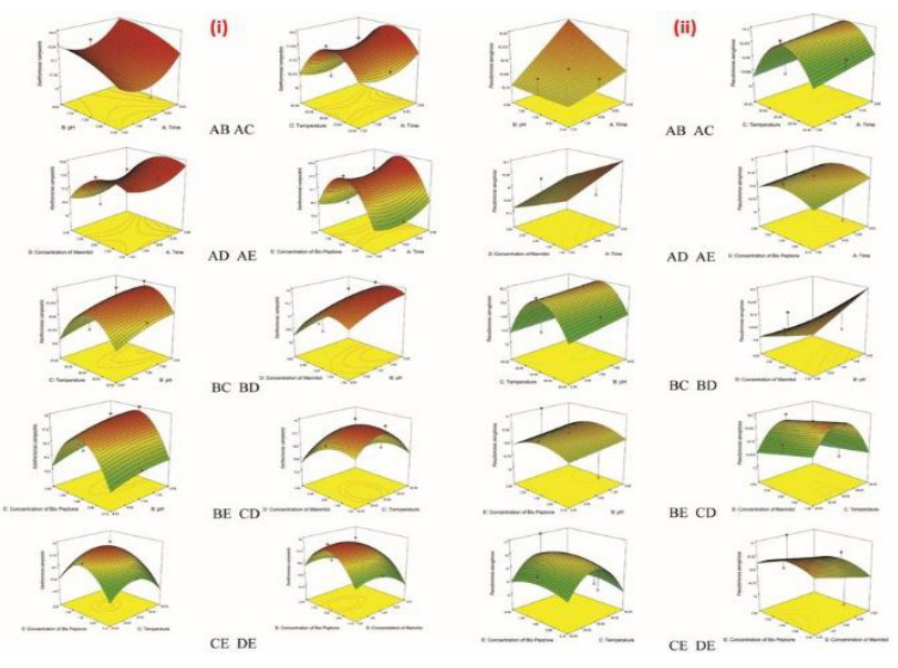

Figure 2: Response surface 3D plots showing the interactive effects of selective variables on Zone of inhibition $(\mathrm{mm})$ of the bioactive compound production by Nonomuraea longicatena VSM-16 against (i) $X$. campestris, (ii) $P$. aeruginosa response.
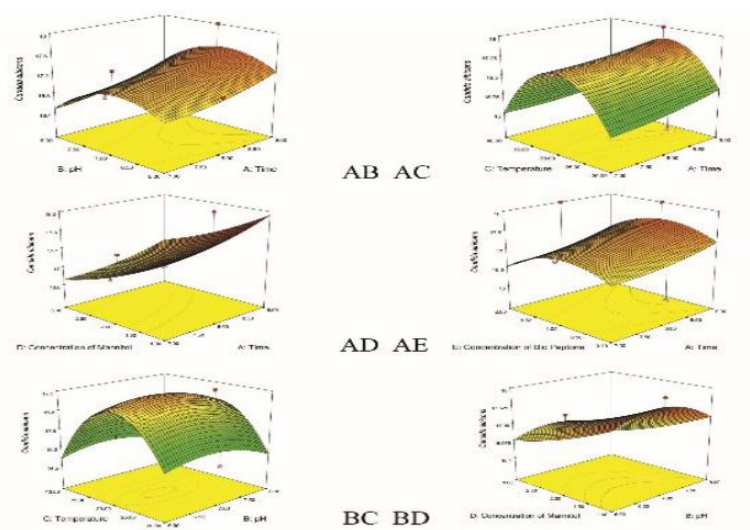

$\mathrm{AD} \mathrm{AE}$
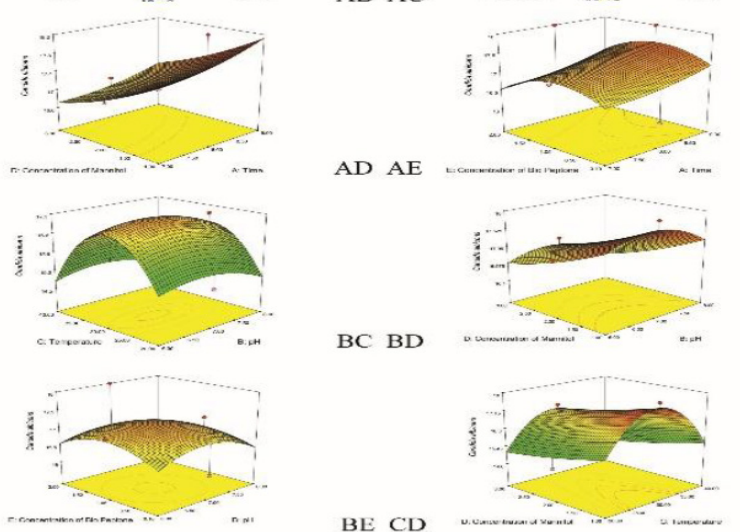

$\mathrm{BC}$ BD
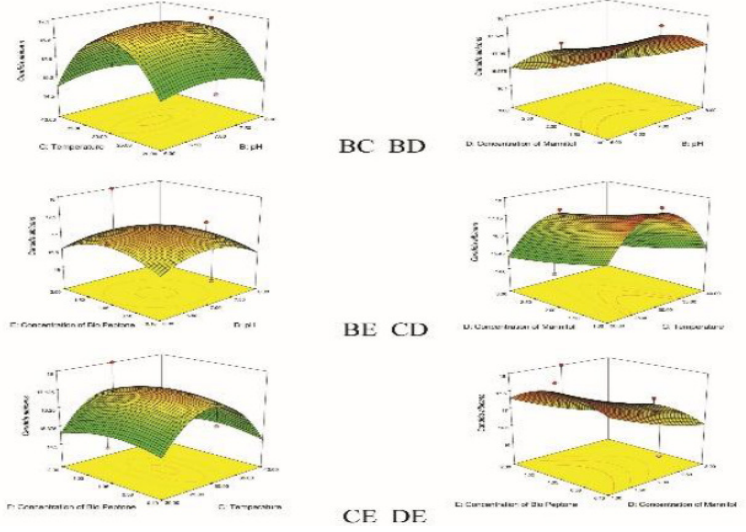

Figure 3: Response surface 3D plots showing the interactive effects of selective variables on Zone of Inhibition $(\mathrm{mm})$ of the bioactive compound production by Nonomuraea longicatena VSM-16 against response C. albicans.

that the $p$-values of all the six response were $<0.0001$ indicating the model was significant.

The profiles of Nonomuraea longicatena (VSM 16) (KU507597) growth and limiting substrate utilization results obtained from shake flask experiments and model kinetics were compared in Figure 4 (a) - (f) display the comparison of experimental versus model predicted zones of inhibition of bioactive metabolite on media inoculated with S. aureus, S. mutans, X. campestris, P. aeruginosa and C. albicans over the time. From all the profiles, it was observed that model predicted and experimental acquired values show very good fit. Biokinetic parameters used in the mathematical model equations were also estimated and are tabulated
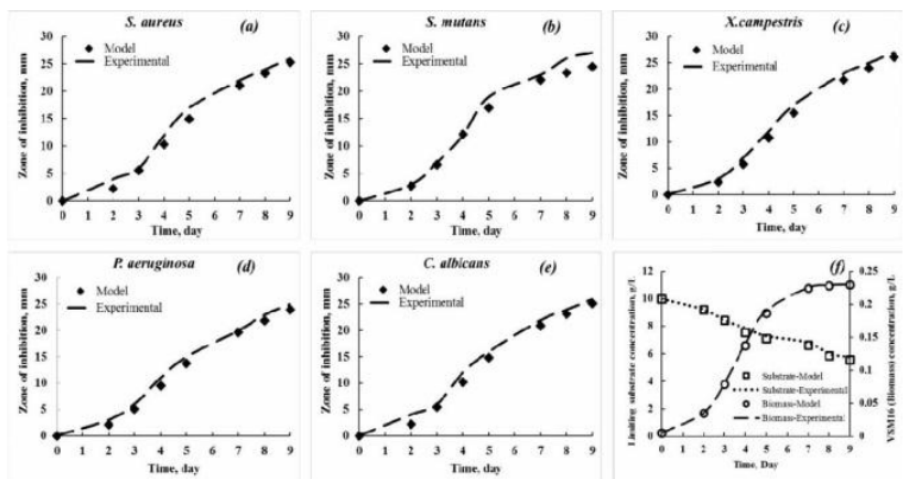

Figure 4: Comparison of experimental and model predicted kinetics (a)-(e): for zone of inhibition $(\mathrm{mm})$; $(f)$ : for biomass growth $(\mathrm{g} / \mathrm{L})$, substrate utilization $(\mathrm{g} / \mathrm{L})$.

Table 3: Estimated kinetic parameters using L, LILP, LIMLP model equations.

\begin{tabular}{|c|c|c|c|c|c|}
\hline $\begin{array}{c}\text { Kinetic } \\
\text { Parameters }\end{array}$ & $\begin{array}{c}\text { S. } \\
\text { aureus }\end{array}$ & $\begin{array}{c}\text { S. } \\
\text { mutans }\end{array}$ & $\begin{array}{c}X \\
\text { campestris }\end{array}$ & $\begin{array}{c}P . \\
\text { aeruginosa }\end{array}$ & $\begin{array}{c}\text { C. } \\
\text { albicans }\end{array}$ \\
\hline \multicolumn{6}{|c|}{ Logistic (L) Model Parameters } \\
\hline$\mu \max \left(\mathrm{d}^{-1}\right)$ & \multicolumn{5}{|c|}{1.05} \\
\hline$R 2$ & \multicolumn{5}{|c|}{0.99} \\
\hline$X 0(\mathrm{~g} / \mathrm{L})$ & \multicolumn{5}{|c|}{0.005} \\
\hline$X m(g / L)$ & \multicolumn{5}{|c|}{0.231} \\
\hline \multicolumn{6}{|c|}{ Logistics incorporated Modified Luedeking-Piret (LIMLP) Model parameters } \\
\hline$\gamma($ g.S/g.X) & \multicolumn{5}{|c|}{12.46} \\
\hline$R 2$ & \multicolumn{5}{|c|}{0.91} \\
\hline$\eta($ g.S $/($ g.X.d $))$ & \multicolumn{5}{|c|}{1.125} \\
\hline \multicolumn{6}{|c|}{ Logistics incorporated Luedeking-Piret (LILP) Model parameters } \\
\hline$a(\mathrm{~mm} / \mathrm{g} . \mathrm{X})$ & 65.06 & 85.08 & 68.26 & 58.84 & 64.25 \\
\hline$R 2$ & 0.91 & 0.88 & 0.93 & 0.93 & 0.92 \\
\hline$\beta(\mathrm{mm} /($ g.X.d $))$ & 8.65 & 4.32 & 8.65 & 8.65 & 8.65 \\
\hline
\end{tabular}

Table 4: Comparison of zones of inhibition $(\mathrm{mm})$ from shake-flask experiments and from model.

\begin{tabular}{cccccc}
$\begin{array}{c}\text { Maximum } \\
\begin{array}{c}\text { Zone of } \\
\text { Inhibition }(\mathrm{mm})\end{array}\end{array}$ & $\begin{array}{c}\text { S. } \\
\text { aureus }\end{array}$ & $\begin{array}{c}\text { S. } \\
\text { mutans }\end{array}$ & $\begin{array}{c}X . \\
\text { campestris }\end{array}$ & $\begin{array}{c}P . \\
\text { aeruginosa }\end{array}$ & $\begin{array}{c}C . \\
\text { albicans }\end{array}$ \\
\hline Experimental & 26 & 27 & 27 & 25 & 26 \\
Model fitted & 25.36 & 24.5 & 26.07 & 23.95 & 25.17 \\
\hline
\end{tabular}

in Table 3 which shows determination coefficient (R2) values obtained by fitting L, LILP and LIMLP models to the experimental data were found to be high, thus revealing good precision of the models. Values of growth and non-growth-related product parameters, $\alpha$ and $\beta$, were estimated using LILP model and a higher $\alpha$ values than $\beta$ confirmed that bioactive metabolite production by the strain is more growth related than non-growth related in shake flask. The simulated parameters, $\gamma$ and $\eta$, of LIMLP model are also in good agreement with the experimental values, implies that this model is more appropriate to symbolize restraining substrate utilization kinetics in bioactive metabolite production by N. longicatena VSM 16. Further, zones of inhibition from agar diffusion assessments are much like model anticipated values (Table 4). 


\section{CONCLUSION}

A novel actinobacterium Nonomuraea longicatena VSM-16 was able to produce bioactive metabolites under the influence of the Incubation time, $\mathrm{pH}$, Temperature, Concentrations of mannitol and biopeptone. Application of the RSM based optimization of the significant factors and their interactive effects to produce bioactive metabolites and parameters obtained were in consistent with experimental values of the bioactive metabolite production using VSM-16. The statistical parameters values obtained indicate that the models for responses match the experimental facts accurately. The optimized process parameters were 8 days of incubation time, $\mathrm{pH}$ at 8 , temperature at $30^{\circ} \mathrm{C}$ and concentrations of mannitol and biopeptone was found to be $2 \%$ and $1.5 \%$, respectively. Under this optimal point the maximum responses represented as zones of inhibition (in $\mathrm{mm}$ ) from the bioactive metabolite produced using VSM-16. This is the first report on the kinetic modelling for bioactive metabolite production (in terms of zones of inhibition studies) by $N$. longicatena VSM 16. The results obtained are promising and merit for large scale production of the bioactive natural metabolites for novel VSM-16 that can be used to find new compounds for the medical application.

\section{ACKNOWLEDGEMENT}

All the authors are grateful to Acharya Nagarjuna University, Guntur and Koneru Lakshmaiah Education Foundation, Vaddeswaram, for providing necessary facilities to carryout this work.

\section{CONFLICT OF INTEREST}

The authors declare no conflict of interest.

\section{ABBREVIATIONS}

RSM: Response Surface Methodology; ANOVA: Analysis of Variance; L: Logistic; LILP: Logistic Incorporated Leudeking Piret; LIMLP: Logistic Incorporated Modified Leudeking Piret; YMD: Yeast Extract Malt Extract Dextrose.

\section{REFERENCES}

1. Manivasagan P, Venkatesan J, Sivakumar K, Kim SK. Pharmaceutically active secondary metabolites of marine actinobacteria. Microbiol Res. 2014;169(4):262-78.

2. Gao $X, L u Y, X i n g Y, M a Y, L u J, B a o W$, et al. A novel anticancer and antifungus phenazine derivative from a marine actinomycete BM-17. Microbiol Res. 2012;167(10):616-22

3. Pietra F. Secondary metabolites from marine microorganisms: Bacteria, Protozoa, algae and Fungi. Achievements and prospects. Nat Prod Rep. 1997; 14(5):453-64.

4. Holkar S, Begde D, Nashikkar N, Kadam T, Upadhyay A. Rhodomycin analogues from Streptomyces purpurascens: Isolation, characterization and biological activities. Springer Plus. 2013;2(1):93.

5. Bundale S, Begde D, Nashikkar N, Kadam T, Upadhyay A. Optimization of culture conditions for production of bioactive metabolites by Streptomyces spp. Isolated from soil. Adv Microbiol. 2015;5(06):441.

6. Olano C, Méndez C, Salas J. Antitumor compounds from marine Actinomycetes. Mar Drugs. 2009;7(2):210-48.

7. Usha MK, Sudhakar P, Sreenivasulu K, Vijayalakshmi M. Optimization of Culturing Conditions for Improved Production of Bioactive Metabolites by Pseudonocardia sp. VUK-10. Mycobiology. 2011;39(3):174-81.

8. Mangamuri UK, Vijayalakshmi M, Poda S, Agasar D. Optimization of the cultural parameters for improved production of antimicrobial metabolites by Streptomyces gulbargensis DAS 131. Br J Pharm Res. 2014;4(9):1130.

9. Krishnakumar S, Premkumar J, Alexis RR, Ravikumar S. Optimization of potential antibiotic production by salt-tolerant Actinomycetes streptomyces sp.-MSU29 isolated from marine sponge. Int J Appl Bioeng. 2011;5(2):12-8.

10. Chen FL, Wei YM, Zhang B, Ojokoh AO. System parameters and product properties response of soybean protein extruded at wide moisture range. J Food Eng. 2010;96(2):208-13.

11. Deepak V, Kalishwaralal K, Ramkumarpandian S, Babu SV, Senthilkumar SR, Sangiliyandi G. Optimization of media composition for Nattokinase production by Bacillus subtilis using response surface methodology. Bioresour Technol. 2008;99(17):8170-4

12. Souagui Y, Tritsch D, Grosdemange-Billiard C, Kecha M. Optimization of antifungal production by an alkaliphilic and halotolerant Actinomycete, Streptomyces sp. SY-BS5, using response surface methodology. J Mycol Med. 2015;25(2):108-15.

13. Kontogiannopoulos KN, Patsios SI, Karabelas AJ. Tartaric acid recovery from winery lees using cation exchange resin: Optimization by Response Surface Methodology. Sep Purif Technol. 2016;165:32-41.

14. Ganduri VR, Mangamuri U, Vijayalakshmi M, Poda S. Model-based kinetic parameters estimation in batch Pullulan fermentation using Jaggery as substrate. J Chem Pharm Res. 2016;8(3):217-24.

15. Rajendran A, Thangavelu V. Evaluation of various unstructured kinetic models for the production of protease by Bacillus sphaericus MTTC511. Eng Life Sci. 2008;8(2):179-85.

16. Znad H, Blažej M, Báleš V, Markoš J. A kinetic model for gluconic acid production by Aspergillus niger. Chem Pap. 2004;58(1):23.

17. Dhanasekar R, Viruthagiri T, Sabarathinam PL. Poly (3-hydroxy butyrate) synthesis from a mutant strain Azotobacter vinelandii utilizing glucose in a batch reactor. Biochem Eng J. 2003;16(1):1-8.

18. Heleno SA, Diz P, Prieto MA, Barros L, Rodrigues A, Barreiro MF, et al. Optimization of ultrasound-assisted extraction to obtain mycosterols from Agaricus bisporus $\mathrm{L}$. by response surface methodology and comparison with conventional Soxhlet extraction. Food Chem. 2016;197:1054-63.

19. Li HX, Lu ZM, Geng Y, Gong JS, Zhang XJ, Shi JS, et al. Efficient production of bioactive metabolites from Antrodia camphorata ATCC 200183 by asexual reproduction-based repeated batch fermentation. Bioresour Technol. 2015;194:334-43.

20. Cheng KC, Demirci A, Catchmark JM, Puri VM. Modeling of Pullulan Fermentation by Using a Color Variant Strain of Aureobasidium pullulans. Journal of Food Engineering. 2010;98(3):353-9.

21. Iqbal UM, Kumar VS, Gopalakannan S. Application of Response Surface Methodology in optimizing the process parameters of Twist Extrusion process for AA6061-T6 aluminum alloy. Measurement. 2016;94:126-38.

22. Managamuri U, Vijayalakshmi M, Poda S, Ganduri VR, Babu RS. Optimization of culture conditions by response surface methodology and unstructured kinetic modeling for bioactive metabolite production by Nocardiopsis litoralis VSM-8. 3 Biotech. 2016;6(2):219.

23. Managamuri U, Vijayalakshmi M, Ganduri VR, Rajulapati SB, Bonigala B, Kalyani BS, et al. Isolation, identification, optimization and metabolite profiling of Streptomyces sparsus VSM-30. 3 Biotech. 2017;7(3):217.

24. Yi XS, ShiWX, Yu SL, Li XH, Sun N, He C. Factorial design applied to flux decline of anionic polyacrylamide removal from water by modified polyvinylidene fluoride ultrafiltration membranes. Desalination. 2011;274(1-3):7-12

25. Shahabadi SM, Reyhani A. Optimization of operating conditions in ultrafiltration process for produced water treatment via the full factorial design methodology. Sep Purif Technol. 2014;132:50-61.

26. Onsekizoglu P, Bahceci KS, Acar J. The use of factorial design for modeling membrane distillation. J Memb Sci. 2010;349(1-2):225-30.

27. Köse TE. Agricultural residue anion exchanger for removal of dyestuff from wastewater using full factorial design. Desalination. 2008;222(1-3):323-30.

28. Xiangli F, Wei W, Chen $Y$, Jin W, Xu N. Optimization of preparation conditions for polydimethylsiloxane (PDMS)/ceramic composite pervaporation membranes using response surface methodology. J Memb Sci. 2008;311(1-2):23-33.

29. Woodall WH, Montgomery DC. Research issues and ideas in statistical process control. J Qual Tech. 1999;31(4):376-86.

30. Chen XC, Bai JX, Cao JM, Li ZJ, Xiong J, Zhang L, et al. Medium optimization for the production of cyclic adenosine $3^{\prime}, 5^{\prime}$-monophosphate by Microbacterium sp. no. 205 using response surface methodology. Bioresour Technol. 2009;100(2):919-24

31. Shirvan KM, Mamourian M, Mirzakhanlari S, Ellahi R, Vafai K. Numerical investigation and sensitivity analysis of effective parameters on combined heat transfer performance in a porous solar cavity receiver by response surface methodology. Int J Heat Mass Transf. 2017;105:811-25

32. Yatish KV, Lalithamba HS, Suresh R, Arun SB, Kumar PV. Optimization of scum oil biodiesel production by using response surface methodology. Process Saf Environ Prot. 2016;102:667-72.

33. Lin Q, Li H, Ren J, Deng A, Li W, Liu C, et al. Production of Xylooligosaccharides by microwave-induced, organic acid-catalyzed hydrolysis of different xylan-type hemicelluloses: optimization by response surface methodology. Carbohydr Polym. 2017;157:214-25. 